\title{
The Intertemporal Stability of the Concentration- Margins Relationship in Dutch and U.S. Manufacturing
}

\author{
YVONNE PRINCE and ROY THURIK* \\ EIM Small Business Research and Consultancy, P.O. Box 7001,2701 AA Zoetermeer, The Necheriands; \\ Centre for Advanced Small Business Economics, Erasmus University Rotterdam, P.O. Box 1738, 3000 \\ DR Rotterdam, The Netherlands
}

\begin{abstract}
Factors influencing price-cost margins are investigated using a rich panel data base of the Dutch manufacturing sector. Attention is devoted to the intertemporal stability of the relationship explaining price-cost margins and to a comparison with U.S. results, Our results indicate that isolated cross-section analyses can be misleading. Evidence is provided for similarities and dissimilarities between the U.S. and the Netherlands when explaining price-cost margins. Dutch margins are infuenced by industry-specific factors such as sales changes, import competition, capital intensity and operating expenses. Domestic seller concentration, aggregate capacity utilization and export intensity play no distinct roles.
\end{abstract}

Key words. Price-cost margins, cyclical influences, averaged panel data.

\section{Introduction}

The relation between seller concentration and prices or price-cost margins has received abundant attention in the industrial organization literature. ${ }^{1}$ Its stability over time has received less attention because of a lack of systematic longitudinal data. Limited instances of the instability of the concentration-margins relationship can be found in Neumann, Böbel and Haid (1983), Frantzen (1986) and Odagiri and Yamashita (1987). ${ }^{2}$ The Japanese results in Odagiri and Yamashita point at procyclical effects in price-cost margins which increase with seller concentration. In one of the few European studies, Neumann, Böbel and Haid find a positive impact of seller concentration on price-cost margins in business cycle upswings in Germany. By contrast, Frantzen finds little evidence of procyclical adjustment in the markup over cost in Belgian manufacturing. In none of these studies an extensive empirical investigation of price-cost margins based on panel data is made and none pay attention to a comparison with established U.S. findings. Our study is the first attempt to fill this gap.

A major study of the instability of the concentration-margins relationship was conducted by Domowitz, Hubbard and Petersen ${ }^{3}$ (1986a and 1986b) - DHP for short. In that study, data from the U.S. Census of Manufacture are used ${ }^{4}$ for a 24-year period (1958 through 1981) and for 1854 -digit industries. ${ }^{5}$ Its key findings 
are that price-cost margins are more procyclical in concentrated than in less concentrated industries ${ }^{6}$ and that import competition is higher in concentrated than in less concentrated industries. ${ }^{7}$ These conclusions are drawn from the significance of the coefficients of the interaction between the concentration ratio and the economy-wide unemployment, and between the concentration ratio and the import-sales ratio in regressions where many independent variables play a role. Their result that industry-specific price-cost margins are affected by aggregate demand changes rather than by industry-specific demand changes is surprising.

The aim of the present study is to investigate Dutch manufacturing price-cost margins and to compare the U.S. results with those using data from the Netherlands. An attempt to replicate the two key findings of DHP mentioned above will be made. Both aggregate and industry-specific demand changes will be considered. At the same time, the influence of many other variables on Dutch manufacturing price-cost margins will be investigated. Dutch manufacturing data are available for a 12-year period (1975 through 1986) and for 66 3-digit industries. Comparison of U.S. results with those of other OECD countries is particularly meaningful, since the U.S. with its large, closed market is no typical case. ${ }^{8}$ Furthermore, the unambiguity of the U.S. results stands out among many weaker results for other countries and needs corroboration. Straightforward generalisation of the U.S. findings can be misleading. This will be illustrated by the fact that the Dutch results do not support DHP's two key findings.

This article is organized as follows. In Section II preliminary evidence is provided on Dutch manufacturing price-cost margins and some variables explaining them as well as on the instability of their relationship. Section III concentrates on a comparison between the explanation of U.S. and Dutch price-cost margins. Using one model specification (but sometimes different variable definitions) for both countries, the regression results show both similarities and dissimilarities. Section IV is concerned with a further analysis of the explanation of price-cost margins in the Netherlands. Section V presents the principal findings. Some concluding remarks are made in Section VI.

\section{Data and Preliminary Evidence}

Our data set is based mainly on material published by the Netherlands Central Bureau of Statistics. ${ }^{9}$ This material contains data on firms with 10 or more employees. In 1986 our 663 -digit industries cover about $81 \%$ of the entire manufacturing sector ( $\geqslant 10$ employees) in terms of value added and $87 \%$ in terms of employment. ${ }^{10}$

Table I contains means and standard deviations of some important variables like price-cost margin $(P C M)$, concentration ratio (C4), gross investment intensity $(G I / Y)$, sales change $(\stackrel{\circ}{V} / V)$, import-sales ratio $(I / S)$ and export intensity $(E X)$. Price-cost margins appear to decline in the period 1976-1982 and to increase from 1982-1986. Dutch price-cost margins are consistently lower than their U.S. 
Table I. Sample means and standard deviations calculated on the basis of averaged data of 66 Dutch manufacturing industries ${ }^{\mathrm{a}}$

\begin{tabular}{llllllll}
\hline Year & $P C M$ & $C 4$ & $G I / Y$ & \multicolumn{1}{l}{$V(V$} & $l / S$ & $E X$ \\
\hline 1975 & $0.166(0.06)$ & $0.384(0.21)$ & $0.704(0.61)$ & $-0.057(0.10)$ & $0.489(0.18)$ & $0.361(0.23)$ \\
1976 & $0.174(0.06)$ & $0.384(0.21)$ & $0.641(0.53)$ & $0.076(0.10)$ & $0.501(0.18)$ & $0.366(0.23)$ \\
1977 & $0.170(0.06)$ & $0.387(0.21)$ & $0.598(0.42)$ & $0.022(0.08)$ & $0.499(0.18)$ & $0.360(0.22)$ \\
1978 & $0.169(0.07)$ & $0.390(0.21)$ & $0.588(0.40)$ & $0.013(0.07)$ & $0.499(0.18)$ & $0.340(0.22)$ \\
1979 & $0.169(0.06)$ & $0.390(0.21)$ & $0.562(0.38)$ & $0.020(0.06)$ & $0.514(0.19)$ & $0.355(0.22)$ \\
1980 & $0.167(0.06)$ & $0.394(0.21)$ & $0.549(0.38)$ & $0.007(0.08)$ & $0.520(0.18)$ & $0.362(0.22)$ \\
1981 & $0.160(0.06)$ & $0.395(0.21)$ & $0.549(0.40)$ & $-0.017(0.10)$ & $0.522(0.18)$ & $0.382(0.22)$ \\
1982 & $0.158(0.05)$ & $0.399(0.22)$ & $0.547(0.42)$ & $-0.025(0.08)$ & $0.527(0.19)$ & $0.390(0.22)$ \\
1983 & $0.166(0.05)$ & $0.399(0.22)$ & $0.522(0.34)$ & $0.013(0.07)$ & $0.539(0.18)$ & $0.394(0.22)$ \\
1984 & $0.177(0.06)$ & $0.401(0.22)$ & $0.475(0.28)$ & $0.046(0.11)$ & $0.550(0.19)$ & $0.402(0.23)$ \\
1985 & $0.179(0.06)$ & $0.399(0.22)$ & $0.448(0.24)$ & $0.054(0.06)$ & $0.555(0.20)$ & $0.404(0.23)$ \\
1986 & $0.191(0.07)$ & $0.381(0.22)$ & $0.453(0.21)$ & $0.026(0.07)$ & $0.549(0.20)$ & $0.398(0.23)$ \\
\hline
\end{tabular}

${ }^{2}$ Precise variable definitions are in Sections III and IV.

counterparts. See DHP (1986a, Table 1, p. 4), where the average price-cost margin is reported to be 0.273 in the period from 1974-1981. In De Jong (1991, Table I, p. 11) it is shown that average profit rates of the largest companies in both countries differ considerably. The profit rate (as a percentage of sales) of the 40 largest firms in the U.S. is $9.8 \%$ whereas that of the 11 largest firms in the Netherlands is $6.9 \%$ (and below $5.5 \%$ when firms run in Anglo-Saxon management style are eliminated). De Jong (1991) argues that, in general, firms in Germanic countries (Germany, the Netherlands, Switzerland, Austria and Scandinavia), where it is virtually impossible to take over against the will of the firms' leaders, show a tendency towards sales growth at lower profit levels than firms in AngloSaxon countries (U.K. and U.S.). In the Anglo-Saxon countries firms run the risk of being taken over if their strategy deviates from profit maximization due to a high shareholders' pressure for short-term gains. Furthermore, there is evidence of higher rates of return for American plants in the Netherlands when compared to their Dutch rivals. A comparison between rates of returns on foreign direct investment in the Netherlands of EC countries and the U.S. shows that the average rate of return of firms based in the U.S. is more than three times as high as those based in EC countries ${ }^{11}$ (Van Nieuwkerk and Sparling, 1985).

The Dutch mean $C 4$ ratio is remarkably stable over time and comparable to that in the U.S. ${ }^{12}$

Gross investment intensity, defined as the ratio between cumulative investments in the preceding 10 years and output, declines over the period 1975-1985, This tendency is surprising at first sight. However, it is understandable if one realizes that our period contains the recession-led decline period from 1977-1982. Furthermore, there has been a general decline in investments in plants and sites due to technological changes enabling less space-intensive production. And finally, the contracting out of services (with a shift of investments from manufacturing to 
Table II. A time series of cross-sectional regression results ${ }^{\mathrm{a}}$ for 66 Dutch manufacturing industries.

\begin{tabular}{lllllll}
\hline Year & Intercept & \multicolumn{1}{l}{$C 4$} & $G I / Y$ & \multicolumn{1}{l}{$(I / S)$} & \multicolumn{1}{l}{ V/V } & $\bar{R}^{2}$ \\
\hline 1975 & $0.130(5.6)$ & $0.084(2.3)$ & $0.032(2.7)$ & $-0.017(-0.4)$ & $0.197(2.4)$ & 0.193 \\
1976 & $0.148(6.4)$ & $0.044(1.3)$ & $0.033(2.5)$ & $-0.046(-1.2)$ & $0.151(2.0)$ & 0.174 \\
1977 & $0.142(6.1)$ & $0.024(0.7)$ & $0.058(3.5)$ & $-0.043(-1.1)$ & $0.236(2.7)$ & 0.269 \\
1978 & $0.146(6.3)$ & $0.016(0.5)$ & $0.076(4.5)$ & $-0.064(-1.6)$ & $0.341(3.4)$ & 0.234 \\
1979 & $0.151(6.3)$ & $0.030(0.9)$ & $0.078(4.3)$ & $-0.077(-2.0)$ & $0.097(0.8)$ & 0.247 \\
1980 & $0.156(6.8)$ & $0.047(1.4)$ & $0.066(3.7)$ & $-0.085(-2.3)$ & $0.065(0.7)$ & 0.220 \\
1981 & $0.158(7.0)$ & $0.029(0.9)$ & $0.057(3.4)$ & $-0.076(-2.1)$ & $0.063(0.9)$ & 0.177 \\
1982 & $0.153(7.0)$ & $-0.005(-0.2)$ & $0.050(3.2)$ & $-0.042(-1.2)$ & $-0.058(-0.7)$ & 0.151 \\
1983 & $0.149(7.1)$ & $-0.002(-0.1)$ & $0.074(4.5)$ & $-0.039(-1.2)$ & $-0.004(-0.0)$ & 0.230 \\
1984 & $0.127(5.5)$ & $-0.019(-0.6)$ & $0.117(5.4)$ & $-0.010(-0.3)$ & $0.166(2.9)$ & 0.339 \\
1985 & $0.106(4.0)$ & $-0.007(-0.2)$ & $0.155(5.8)$ & $-0.009(-0.3)$ & $0.198(1.9)$ & 0.336 \\
1986 & $0.093(3.6)$ & $0.013(0.4)$ & $0.206(6.8)$ & $-0.014(-0.4)$ & $0.315(3.0)$ & 0.468 \\
& & & & & & \\
$1975-86$ & $0.151(22.4)$ & $0.019(2.0)$ & $0.061(12.6)$ & $-0.045(-4.2)$ & $0.150(6.8)$ & 0.222 \\
\hline
\end{tabular}

${ }^{3}$ Dependent variable: price-cost margin. $T$-values are in parentheses.

service industries) and leasing and hiring instead of buying became common business practice in the $1980 \mathrm{~s}$.

There have been considerable fluctuations in mean sales changes during the recession period from 1980 to 1982 and the succeeding recovery period. We also recognize the effect of the oil crisis in 1975 and the vehement recovery in 1976 . A clear linkage can be observed between the pattern of the mean sales changes and that of the mean level of price-cost margins.

There were general upward drifts in both import-sales ratios ${ }^{13}$ and export intensities. Particularly in the period from 1978 to 1985 there was a monotonous upward movement.

The inspection of the yearly sample means shows that there is reason to surmise that the concentration-margins relationship is not stable over time. The results of a series of cross-sectional regressions are given in Table II to further demonstrate this instability. Price-cost margin is the dependent variable, whereas concentration ratio $(C 4)$, investment intensity $(G I / Y)$, import-sales ratio $(I / S)$ and sales change $(\check{V} / V)$ are the independent variables. Our approach is similar to that of DHP (1986a, p. 5), which is again inspired by that of Collins and Preston (1969). The use of $I / S$ in this stage of the analysis is proposed by Peltzman (see Salinger, 1990). The use of $\stackrel{0}{V} / V$ is induced by the results of Table $\mathrm{I}$. The estimation results show that the coefficient of $C 4$ is not significantly different from zero in all years except 1975. Ignoring significance, we see that the coefficient tends to decline over time. The coefficient of $G I / Y$, our indicator of capital-intensity, is significantly greater than zero for all years. We also note that this coefficient increases over time. This implies that the reward on capital-intensity has increased over time. This has to do with the changing composition of investments: less investments in plants and sites and more in machinery and other equipment. The latter category 
requires a higher depreciation rate. The coefficient of $I / S$ is below zero in all years, but only significantly so in the period 1979-1981. The coefficient of $\dot{V}^{\circ} V$ is never significantly below zero. It is not significantly different from zero in the period 1979-1983. The procyclicality of margins is frustrated in a sluggish economy. At this preliminary stage of our analysis we have to conclude that there is hardly any relation between price-cost margins and the independent variables of Table II, apart from investment intensity, and, if there is any relation, then it is not a stable one. The latter conclusion is mainly based upon a declining (but insignificant) effect from seller concentration, upon the changing role of investment intensity, and upon the trough in the influence of industry-specific sales changes in explaining price-cost margins. ${ }^{14}$

The best answer to the question "what happened to the concentration-margins relationship?" raised in Salinger (1990) is simply "nothing". ${ }^{15}$ The relationship cannot be statistically established using the above regression for any year except 1975. An F-test on the equality of the coefficients of $C 4$ given that the coefficients of the other independent variables need not be equal across the period, does not reject the equality of the coefficients of $C 4$.

In the next two sections price-cost margin movements will be analysed in more detail to explicitly establish the role of cyclical and secular impulses. As a starting point, we will consider a model largely identical to that employed by DHP. This model is primarily concerned with interactions between cycles on the one hand and concentration and imports on the other. In Section IV we will present an alternative model tailored to the Dutch situation.

\section{Testing the DHP Key Findings}

In this section we will report on whether price-cost margins in Dutch manufacturing are more procyclical and more sensitive to import competition according to the level of industry concentration. To test this we will use the specification proposed by DHP (1986a, p. 13):

$$
\begin{aligned}
P C M_{i t}= & \alpha_{0}+\alpha_{1} C 4_{i t}+\alpha_{2}(K / Q)_{i t}+\alpha_{3}(A / S)_{i t}+\alpha_{4}(\dot{Y} / Y)_{i t}+ \\
& +\alpha_{5} C 4(\dot{Y} / Y)_{i t}+\alpha_{6}(K / Q)(\grave{Y} / Y)_{i t}+\alpha_{7} U_{t}+\alpha_{8} C 4 U_{i t}+ \\
& +\alpha_{9}(K / Q) U_{i t}+\alpha_{10}(I / S)_{i t}+\alpha_{11} C 4(I / S)_{i t}+v_{i t}
\end{aligned}
$$

where $P C M$ : price-cost margin $=($ value added - payroll $) /($ value added + cost of materials), where value added $=$ value of sales $+\Delta$ inventories - cost of materials; $C 4$ : four-firm concentration ratio; $K / Q$ : capital-output ratio; $A / S$ : advertising-sales ratio; $Y / Y$ : percentage change in industry output; $U$ : economy-wide unemployment rate; $I / S$ : import-sales ratio; $v$ : error term; $i$ : index of industry; $t$ : year of observation.

In this specification the influences of both $K / Q$ and $C 4$ are permitted to vary according to cyclical fluctuations. Both an aggregate $(U)$ and a local $\left(Y^{\circ} / Y\right)$ repre- 
sentation of these conditions are selected. Moreover, the influence of both simple cyclical indicators and that of $A / S$ and $I / S$ is accounted for ${ }^{16}$ Finally, the specification allows for the test whether the degree of concentration affects the influence of import competition on price-cost margins.

\section{A. DATA DIFFERENCES}

Our Dutch data set contains 66 3-digit industries covering 1975-1986, whereas the U.S. data set is constructed using 185 4-digit industries covering the 1958-1981 period. Next to these differences there are also some differences in the way the variables are defined. ${ }^{17}$

First, we have no data on the capital stock per industry. The total amount of fixed capital formation (gross investments) in the preceding 10 years, $G I$, is used to approximate the capital stock. Second, advertising expenditures are not available separately. We use the ratio of the so-called operating expenses and output, $O E / Y$. Operating expenses include all costs except payroll, capital, material and energy costs. ${ }^{18}$ Third, in the Netherlands, like in most EC countries, it is difficult to express the stage of the aggregate business cycle in terms of nationwide unemployment because of its persistent structural character. Instead, we will use aggregate capacity utilization, $C U .{ }^{19}$

\section{B. ESTIMATION RESULTS}

In Table III the ordinary least squares (OLS) and fixed effects (FE) estimation results $^{20}$ of Equation (1) are presented for both the U.S. and the Netherlands. The U.S. results are from DHP (1986a); they are reproduced in full to facilitate our comparison. Let us first discuss the influence of demand fluctuations. Procyclical demand impact on price-cost margins is to be expected on the basis of both a cost and price effect. Given procyclical productivity, upswings will lead to higher industry margins. Given capacity constraints, upswings will lead to higher prices.

For the U.S. we see that industry-specific demand fluctuations do not affect price-cost margins whereas their aggregate counterparts do. This result is surprising since one would expect an industry to be involved with its industry-specific demand fluctuations rather than with changes in the unemployment rate of the economy as a whole. However, the difference between the OLS and the FE estimations for the U.S. makes it difficult to assess the general significance of aggregate demand changes. Evaluated at the sample means for $C 4$ and $K / Q, \partial P C M / \partial U$ exceeds zero when using OLS estimations and is less than zero in the FE case. We tend to interpret these results as being inconclusive: on the whole, there is no autonomous cyclical effect on margins. However, procyclicality increases with increasing degree of industry concentration: $\partial^{2} P C M / \partial U \partial C 4<0$. It also increases with increasing degree of capital-intensity: $\partial^{2} P C M / \partial U \partial(K / Q)<0$. Both results are valid for both 
Table III. Pooled regression results using specification $(1)^{\mathrm{a}}$

\begin{tabular}{|c|c|c|c|c|c|}
\hline \multicolumn{3}{|l|}{$\begin{array}{l}\text { U.S. } \\
\text { 1958-1981 }\end{array}$} & \multicolumn{3}{|l|}{$\begin{array}{l}\text { NL } \\
1975-1986\end{array}$} \\
\hline Variable & OLS & $\mathrm{FE}$ & Variable & OLS & $\mathrm{FE}$ \\
\hline Intercept & $\begin{array}{l}0.130 \\
(8.7)\end{array}$ & & Intercept & $\begin{array}{l}-0.156 \\
(-1.2)\end{array}$ & \\
\hline$C 4$ & $\begin{array}{l}0.142 \\
(8.9)\end{array}$ & $\begin{array}{l}0.095 \\
(6.8)\end{array}$ & $\mathrm{CA}$ & $\begin{array}{l}0.087 \\
(0.3)\end{array}$ & $\begin{array}{l}0.177 \\
(0.8)\end{array}$ \\
\hline$K / Q$ & $\begin{array}{l}0.098 \\
(5.8)\end{array}$ & $\begin{array}{l}0.043 \\
(1.7)\end{array}$ & $G \| / Y$ & $\begin{array}{l}-0.100 \\
(-0.4)\end{array}$ & $\begin{array}{l}0.033 \\
(0.3)\end{array}$ \\
\hline$A / S$ & $\begin{array}{l}1.057 \\
(21.1)\end{array}$ & $\begin{array}{l}0.075 \\
(0.7)\end{array}$ & $O E / Y$ & $\begin{array}{l}1.123 \\
(20.9)\end{array}$ & $\begin{array}{l}0.467 \\
(4.8)\end{array}$ \\
\hline$Y / Y$ & $\begin{array}{l}0.038 \\
(1.5)\end{array}$ & $\begin{array}{l}0.010 \\
(0.7)\end{array}$ & $\dot{Y} / Y$ & $\begin{array}{l}0.010 \\
(0.3)\end{array}$ & $\begin{array}{l}0.010 \\
(0.4)\end{array}$ \\
\hline$C 4(\stackrel{a}{Y / Y})$ & $\begin{array}{l}0.088 \\
(1.5)\end{array}$ & $\begin{array}{l}0.017 \\
(0.5)\end{array}$ & $C 4(\stackrel{Y}{Y} / Y)$ & $\begin{array}{l}-0.116 \\
(-1.5)\end{array}$ & $\begin{array}{l}-0.047 \\
(-0.8)\end{array}$ \\
\hline$(K / Q)(Y / Y)$ & $\begin{array}{l}0.000 \\
(0.0)\end{array}$ & $\begin{array}{l}0.029 \\
(1.0)\end{array}$ & $(G I / Y)(Y / Y)$ & $\begin{array}{l}0.056 \\
(1.8)\end{array}$ & $\begin{array}{l}0.022 \\
(1.2)\end{array}$ \\
\hline$U$ & $\begin{array}{l}1.094 \\
(3.9)\end{array}$ & $\begin{array}{l}0.850 \\
(3.2)\end{array}$ & $C U$ & $\begin{array}{l}0.246 \\
(1.7)\end{array}$ & $\begin{array}{l}0.174 \\
(2.0)\end{array}$ \\
\hline$C 4 U$ & $\begin{array}{l}-0.903 \\
(-2.9)\end{array}$ & $\begin{array}{l}-0.828 \\
(-4.7)\end{array}$ & $\mathrm{CACU}$ & $\begin{array}{l}-0.072 \\
(-0.2)\end{array}$ & $\begin{array}{l}-0.028 \\
(-0.1)\end{array}$ \\
\hline$(K / Q) U$ & $\begin{array}{l}-0.848 \\
(-2.5)\end{array}$ & $\begin{array}{l}-1.438 \\
(-3.7)\end{array}$ & $(G I / Y) C U$ & $\begin{array}{l}0.135 \\
(0.5)\end{array}$ & $\begin{array}{l}-0.086 \\
(-0.7)\end{array}$ \\
\hline$I / S$ & $\begin{array}{l}0.084 \\
(2.6)\end{array}$ & $\begin{array}{l}0.125 \\
(3.1)\end{array}$ & $I / S$ & $\begin{array}{l}-0.076 \\
(-6.0)\end{array}$ & $\begin{array}{l}0.254 \\
(4.5)\end{array}$ \\
\hline$C 4(1 / 5)$ & $\begin{array}{l}-0.252 \\
(-5.6)\end{array}$ & $\begin{array}{l}0.084 \\
(1.3)\end{array}$ & $C 4(I / S)$ & $\begin{array}{l}0.013 \\
(0.3)\end{array}$ & $\begin{array}{l}-0.602 \\
(-3.8)\end{array}$ \\
\hline$n$ & 4440 & 4440 & $n$ & 792 & 792 \\
\hline $\bar{R}^{2}$ & 0.25 & 0.08 & $\bar{R}^{2}$ & 0.56 & 0.20 \\
\hline
\end{tabular}

the OLS and the FE case. Moreover the signs of the coefficients of $C 4, K / Q, A / S$ and $C 4(I / S)$ are in accordance with the expectations of DHP. The positive infuence of import competition on price-cost margins is surprising but at least in the OLS case $\partial P C M / \partial(I / S)$ is below zero at the mean for $C 4$. The effect of competing imports becomes negative if $C 4$ exceeds 0.33 .

For the Netherlands we see that neither industry-specific nor aggregate cyclicalities can be detected. In the OLS case $C 4, G I / Y$ and $C 4(I / S)$ do not contribute to the explanation of price-cost margins, whereas the signs of the coefficients of $O E / Y$ and $I / S$ are significant and in agreement with our expectations. The fixed effects coefficient of import competition is in excess of zero and significantly so. However, incorporating the coefficient of the interaction term $C 4(I / S)$ one sees that the effect of competing imports is negative if $C 4$ exceeds 0.42 . 


\section{SIMILARITIES}

Concentrating on the similarities between the American and the Dutch results we first note that industry-specific demand movements do not affect price-cost margins in either country. Secondly, the advertising-sales ratio in the U.S. and the operating expenses-output ratio in the Netherlands influence margins positively. Clearly this is due to the omission of these cost components when calculating pricecost margins. More relevant is the question whether the coefficient of such cost components differs from unity. Values above (below) unity imply that such cost components have a positive (negative) contribution to the returns net of these components. Interpreting the advertising-sales ratio as a measure of product differentiation advantages of established sellers, we have to conclude that for the U.S. this ratio constitutes no profit raising barrier to entry. Its coefficient does not differ significantly from unity. For the Netherlands, however, the coefficient of operating expenses significantly exceeds unity. In manufacturing industries operating expenses (containing all selling costs including advertising costs) probably is a better measure to establish non-competitive returns than advertising costs (being a part of selling costs). Thirdly, results indicate that import competition can only be expected to affect profits if it limits the ability of domestic firms to exploit monopoly power. That is, if domestic industry structure is such that in the absence of imports, profits in excess of the normal level can be earned. See Hutchinson (1981, p. 258), Caves (1985) and Schmalensee (1989, p. 976). The abolishment of trade barriers for competing imports is likely to squeeze profits only in concentrated industries. This result is not supported by the American FE estimations and the Dutch OLS estimations.

\section{DISSIMILARITIES}

Concentrating on the dissimilarities between the countries we first note that the concentration measure has no influence in the Dutch case. A reason for this may be that domestic concentration measures tell little about the competitive environment in small open economies. A high tradability of manufacturing goods implies that industries in small open economies tend to become international price takers. See Frantzen (1986). Alternatively, C4 might not be an adequate measure for the Dutch case with its high share of giant multinational firms dominating the domestic market. A $C 1$ or $C 2$ measure might prove to be a better representation of the distribution of the domestic market power. See Kwoka (1979) and Prince and Thurik (1993). Secondly, the Dutch investment intensity measure fails to influence price-cost margins. This is probably due to the high correlation between investment intensity and the interactive terms in which investment intensity plays a role. ${ }^{21}$ Thirdly, Dutch profits do not seem to be affected by a measure of aggregate demand movements whereas American do (at least when these movements are considered in connection with $C 4$ and $K / Q$ ). DHP use unemployment, a measure of the national capacity utilization of labour, whereas the capacity 
utilization in terms of value added of the entire manufacturing sector is used in the Netherlands. This difference in definition may account for the divergence in these empirical findings. The American definition of aggregate demand may work largely through the cost side, viz. through input prices set with limited control by the industry. In contrast to this, the Dutch definition of aggregate demand may work also through price setting: the industry may lower prices in the face of a low utilization of its capacity. ${ }^{22}$ Fourthly, the American intercept significantly exceeds zero whereas the Dutch intercept does not. This dissimilarity could be expected on the basis of the consistently higher level of U.S. price-cost margins mentioned in Section II.

Returning to the DHP key findings, we conclude that no procyclicality can be detected in the relation between Dutch price-cost margins and seller concentration but that the effect of import competition is apparently higher in concentrated markets.

\section{A Model for the Netherlands}

The complete absence of a procyclical component in the explanation of Dutch price-cost margins is surprising. We will further investigate this component because the typical DHP specification may limit the possibility of its detection. Therefore, we will amend the test specification proposed by DHP and represented by equation (1). First, export intensity, $E X$, defined as foreign sales divided by total sales, will be inserted as well as the interaction term, C4EX. For an open economy like the Dutch, industry performance cannot be adequately dealt with without the full consideration of all trade flows. The sign of the relation between export intensity and price-cost margins is not straightforward. The struggle for survival on the domestic market may force firms to engage in export activities. This may lead to dumping practices in some cases. See Neumann, Böbel and Haid (1983) and Pugel (1980). The relation may then tend to be negative. There are also references to a positive relation. The riskiness of exporting requires a premium. And the selection of less elastic foreign markets may circumvent the downward pressure on price-cost margins (see Khalilzadeh-Shirazi, 1974; Pagoulatos and Sorenson, 1976). ${ }^{23}$ Clearly, increasing export intensity will lead to a lower significance of the influence of the domestic seller concentration: the coefficient of $C 4 E X$ is expected to be negative. Alternatively, the omission of an interaction variable may be the reason for the low and insignificant influence of $C 4$ reported in Table I.

Secondly, we prefer to use sales rather than output (defined as value of sales plus change in inventories). Sales better reflect the stage of the business cycle. In recession periods output can be higher than sales leading to an increase of inventory. In business cycle upswings sales can be higher than output if products are sold from stock. Below, the variable $V / V$ will denote the relative change in sales. The use of output instead of sales in measuring the industry-specific demand changes in DHP (1986a) may account for its failure to contribute to the explanation of American price-cost margins. 
Thirdly, we leave out aggregate indicators of demand induced movements. Elsewhere they also appear not to contribute to the explanation of Dutch manufacturing price-cost margins. ${ }^{24}$ The openness of the Dutch economy probably limits the usefulness of national or sectoral indicators.

OLS estimation of the amended model yields: ${ }^{26}$

$$
\begin{aligned}
& P C M=0.053+0.030 C 4+0.023 G I / Y+1.120 O E / Y+0.178 V^{\circ} / V \\
& \text { (5.6) (1.0) (4.8) (21.3) (4.8) }
\end{aligned}
$$

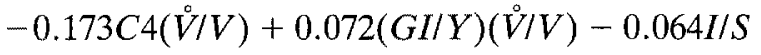

$$
\begin{aligned}
& (-2.3) \\
& (-4.4) \\
& +0.004 C 4(I / S)+0.009 E X-0.016 C 4 E X \quad \bar{R}^{2}=0.58 \text {. }
\end{aligned}
$$

Let us first discuss the impact of industry-specific cycles on price-cost margins: $\partial P C M / \partial(\dot{V} / V)=0.178-0.173 C 4+0.072(G I / Y)$. Since $0<C 4 \leqslant 1$ and gross investments always have positive values, this impact is always positive. Using industry-specific cycles, there is a procyclical movement in price-cost margins, the intensity of which decreases if domestic market concentration increases, and increases with increasing investments. Apparently, cyclical effects cannot be adequately measured in the absence of concentration and investment intensity variables (see DHP, 1986b). The influence of market structure on the relation between price-cost margins and cyclical fluctuation, usually referred to as the intertemporal instability of the relation between market structure and margins, has been discussed elsewhere and investigated both from a theoretical and empirical point of view. We can only add to these inconclusive discussions the empirical fact that given the above approach $\partial^{2} P C M / \partial\left(I^{\circ} / V\right) \partial C 4<0$ for the Netherlands.

Secondly, we see that investment intensity has a positive effect on industry margins which is intensified in upswings: $\partial P C M / \partial(G I / Y)=0.023+0.072(V / V)$. This implies that there is a procyclical element in the pay-off of recent investments. A comparable result is established for the U.S.: $\partial P C M / \partial(K / Q)=0.098-0.848 U$ (see Table III). The procyclical character of the influence of capital-intensity is plausible in view of the fixed costs nature of investments in capital goods. ${ }^{27}$

Thirdly, we observe that import competition squeezes domestic industry margins. The interrelation with the level of concentration can only be established using FE estimations of the DHP specification (see Table III). Export intensity does not seem to have any effect on margins.

\section{A. STABILITY}

Equation (2) is tested on stability in four ways. First, we divide our 66 industries into two groups: 37 industries are classified as consumer goods industries and 29 as producer goods industries. A Chow-test on sample division using equation (2) shows that the pooling of consumer and producer goods industries must be re- 
jected. When looking at the individual estimated coefficients (which we will not fully report here for brevity) we observe only two significant differences. ${ }^{28}$ The influence of seller concentration, $C 4$, is higher in consumer goods industries (generally with a low buyer concentration ${ }^{29}$ ) than in producer goods industries (generally with a high buyer concentration) ${ }^{30} \mathrm{~A}$ high buyer concentration probably offsets the advantages of a high seller concentration by way of the countervailing power hypothesis. The second difference arises when considering the influences of export intensity on margins: the influence of $C 4 E X$ is significantly negative for consumer goods industries whereas that of $E X$ is significantly positive for producer goods industries. This implies that the seller concentration advantages in the consumer goods industries are cancelled out against the disadvantages of an international market and that exporting can pay off in terms of industry margins if the number of buyers is limited such as is the case in producer goods industries.

For the second stability test we split our sample interval into two periods: 19751980 and 1981-1986. The first six-year period is largely characterized by the downward trend of the mean $V / V$ in the period from 1976 to 1980 . The second six-year period is characterized by the upward trend of the mean $V / V$ in the period 1981-1985 (see Table I). A Chow-test on sample division shows that the pooling of the two periods has to be rejected. Inspection of the individual estimated coefficients reveals only two significant differences between the periods. The influence of investment intensity is higher in the recent period than in the early period. This is consistent with the results given in Section II which show a significant growth of the influence of investment intensity in the period 1982-1986. In that preludial section the growth of the influence of investment intensity was attributed to the changing composition of investments. Also the effect of procyclical intensification is higher in the second period. ${ }^{31}$ The other difference concerns the influence of export intensity on margins. The coefficient of $E X$ is significantly negative in the first period and significantly positive in the second, whereas the opposite is found for the coefficients of the interactive term, $C 4 E X$. It pays increasingly to engage in export activities. Apart from this empirical fact, we note that the significance of $C 4$ diminishes with increasing export intensity in the recent period. The significant positive coefficient of $C 4 E X$ in the first period remains somewhat of a mystery. It tells us that exporting activities are more advantageous when the level of domestic market concentration is high. Small firm export efforts probably were not profitable before the recession in the early $1980 \mathrm{~s} .{ }^{32}$

As a third test FE estimations of the amended model are computed:

$$
\begin{aligned}
& P C M=\text { dummies }+0.175 C 4-0.034 G I / Y+0.507 O E / Y+0.0800^{\circ} / V \\
& \text { (2.5) } \quad(-5.9) \\
& \text { (7.2) } \\
& -0.054 C 4(\stackrel{\circ}{V} / V)+0.033(G I / Y)(\stackrel{\circ}{V} / V)+0.188 I / S \\
& (-1.3)
\end{aligned}
$$

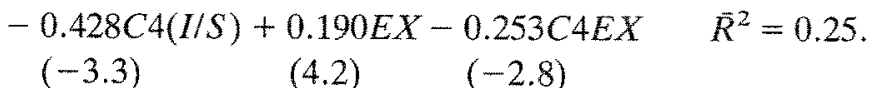


Clearly, a comparison of OLS and FE estimations is no test sensu stricto because their interpretations are not identical. OLS estimations are a mixture of long-run (cross-sectional) and year-to-year (time-series) effects whereas FE estimations can be associated with the consequences of year-to-year changes. It can be computed from (3) that $\partial P C M / \partial(G I / Y)<0$ and that $\partial P C M / \partial C 4<0$ at the sample means for $\mathscr{V} / V, I / S$ and $E X$. Increases in both the level of investments and seller concentration lead to lower price-cost margins. A high level of recent investments leads to a temporary decrease in margins, as does the short-term restructuring effect of an increase of the level of seller concentration. The latter effect probably means that increases in market power are being bought. The coefficient of $O E / Y$, which is less than 1 , implies that operating expenses have a short-run negative effect on returns. The coefficients of $I / S$ and $C 4(I / S)$ are comparable to those reported in Table III. Year-to-year changes in the export intensity are positively related to price-cost margins.

As a fourth test various instrumental variable schemes are considered to check on potential simultaneity problems. Obvious candidates for endogeneity are concentration, the import-sales ratio, export intensity and the operating expensesoutput ratio. The first two are justified because a high domestic profitability attracts entry by both domestic and foreign firms and hence affects the levels of concentration and imports. The latter two because price, export and cost decisions are taken in a simultaneous fashion when a time span of one entire year is considered. The results of these schemes do not differ substantially from the OLS results. A statistical test as described in detail in Geroski (1982, pp. 148-151) is also performed. ${ }^{33}$ The null hypothesis that the four candidates are exogenous cannot be rejected, i.e. no endogeneity is signalled. However, the significance of these and similar test schemes is limited since there are very few intrinsically exogenous variables at this level (see Schmalensee, 1989, pp. 953-956).

\section{Principal Findings}

Thus far, many results have come up in this paper. The principal findings are:

1. For the Netherlands the relation between price-cost margins and explanatory variables is unstable over time. There is a procyclical effect $(\partial P C M / \partial(V / V)>0)$ which diminishes with increasing industry concentration and which expands with increasing investment intensity. Moreover, the role of investment intensity and export intensity differs between the pre-recession period from 1975 to 1980 and the recession/post-recession period from 1981 to 1986.

2. Dutch cyclicalities can only be detected using industry-specific demand fluctuations, whereas U.S. cyclicalities appear solely to depend upon nation-wide unemployment. Further research on the detection of cyclicalities is definitively required. A tentative explanation may be that the relatively low average returns forced Dutch firms to follow meticulously the developments in their specific market. The closedness and vastness of the American economy allowed firms to follow 
its general waves. The leading role of U.S. firms on world markets in the $1960 \mathrm{~s}$ and the 1970 s added to this phenomenon. The U.S. cyclical pattern also differs from the Dutch in that there is no distinct cyclical influence on price-cost margins. ${ }^{34}$ However both increasing industry concentration and increasing capital-intensity bring about more procyclical price-cost margins. The Dutch findings are in agreement with Stylized Fact 4.4 of Schmalensee (1989, p. 972) which states that "recent growth in revenue is positively correlated with measured profitability". The degree of the Dutch seller concentration exerts a downward pressure of this correlation. In other words, it can be interpreted as to have a positive effect on the transmission speed of cost variations into prices. In concentrated industries firms will probably avoid the (secret) lagging of prices behind costs because it is easy to detect by the few others and will evoke retaliation by them (see Ginsburgh and Michel, 1988). The reverse is found in the U.S. The degree of U.S. seller concentration has a negative effect on the transmission speed of cost movements into prices. Probably, the absence of significant foreign competition creates room for procyclical collusive gains.

3. The domestic four-firm concentration ratio appears to have little effect in an open economy like the Dutch, even when it is corrected for the influences of business cycles, trade flows, buyer concentration, etc.

4. For both the U.S. and the Netherlands there are indications that import competition is higher in concentrated than in less concentrated industries. For both the U.S. and the Netherlands there is a procyclical element in the infiuence of capital-intensity on price-cost margins. Both of these findings are not uncommon in empirical studies of structure and performance (see Schmalensee, 1989).

5. The coefficient of the operating expenses-output ratio is in excess of one when explaining price-cost margins in the Netherlands. Operating expenses include all costs except payroll, capital, material and energy costs; they contain selling costs. Since these costs are omitted from the variable costs when calculating price-cost margins it derives that in manufacturing there are profit raising noncompetitive returns to be gained from their outlay.

\section{Concluding Remarks}

This paper addresses the issue of the business cycle influence on the relationship explaining price-cost margins in Dutch manufacturing for a recent period (19751986). Variables considered to explain price-cost margins are the four-firm concentration ratio, investment intensity ( $\approx$ capital-intensity), operating expenses-output ratio, sector-wide and industry-specific demand movements, import-sales ratio and export intensity. Particular attention is devoted to the comparison with a major recent study of the U.S. manufacturing sector by DHP (1986a) dealing with the intertemporal stability of the relation between price-cost margins and the degree of seller concentration. There is considerable value added to be gained from crossnational comparisons, particularly if a large, closed economy such as the U.S. is 
compared to the small, open one of the Netherlands. Moreover, the Dutch experience is probably more typical and more generalizable for other OECD countries with the exception of Japan. Moreover, there are very few cases in which a crossnational comparison is made using extensive panel data sets. Both the American (185 industries, 24 years) and the Dutch (66 industries, 12 years) span a considerable number of industries and years. In 1986 DHP assert that "To our knowledge, no studies have employed panel data to investigate the connection between market structure and cyclical behaviour" (DHP, 1986b, p. 22). Apart from the follow-up study by Salinger (1990) and the recent investigation based on FTC Line-ofBusiness data by Mueller and Sial (1993), ours is the third in this area. The richness of our data set in terms of industry-specific variables is comparable to that employed by DHP.

We conclude that the two key findings of DHP for the large, closed economy of the U.S. are not confirmed for the small, open economy of the Netherlands. In particular, Dutch price-cost margins are less procyclical in concentrated than in less concentrated industries. The American are more procyclical. Dutch import competition is found to be higher in concentrated than in less concentrated industries only when using FE estimations. This suggests that the result is only valid in the short run. Furthermore, Dutch price-cost margins are, as might be expected, affected by industry-specific demand changes, whereas American are influenced only by the economy-wide unemployment rate.

The current study is one out of a long tradition in industrial organisation focusing on descriptive, non-structural analyses and searching for empirical regularities with the aid of relatively simple, reduced-form specifications. No formal mathematical model lies at the basis of our endeavour. No explicit modelling of the departures from equilibrium (of the error correction type) are consistently employed. No long-run equilibrium is thoroughly discussed. The emphasis of our study is on the replication of results which have been obtained earlier for the U.S. In doing so we are able to compare and contrast the results obtained for two different countries, two different periods, two different specifications, two different sets of variable definitions and two different teams of researchers. This adds considerably to a one-country study in which one always runs the risk of bending one's hypotheses around the typical data opportunities. Especially when a country has peculiarities, like the vastness and the closedness of the U.S. market, one should be careful about generalising findings. Evidence starts to become convincing when it is robust to differences of the above kinds. Particularly where the support of formal modeling is weak, the attempt for cross-national replication of results may prove valuable. Empirical regularities which hold across national boundaries cannot fail to constitute a fruitful starting point for a matching process in which the emphasis now is on formal modeling. 


\section{Notes}

* This research was sponsored in part by the Economics Research Foundation, which is part of the Netherlands Organization for Scientific Research. We wish to thank H. W. de Jong, Leo Sleuwaegen, David Audretsch and Aad Kleijweg for their useful comments.

${ }^{1}$ See the reviews in Cubbin (1988), Schmalensee (1989) and Scherer and Ross (1990). See also Salinger (1990) for a short historical review of the relation between research results and policy implications.

${ }^{2}$ See also the references in Domowitz, Hubbard and Petersen (1986a), Martin (1988) and Scherer and Ross (1990). Attention is also devoted to this issue from a theoretical point of view. Deliberations, however, do not lead to an unambiguous result. See Domowitz, Hubbard and Petersen (1986b) and Ginsburgh and Michel (1988) for a discussion and references.

${ }^{3}$ A follow-up study is Salinger (1990) where the cross-section results of DHP (1986a) are extended up to 1984.

${ }^{4}$ Recently, the study of Mueller and Sial (1993) has contributed to the debate on the intertemporal stability of the concentration-profit relationship. They investigate the use of FTC Line-of-Business (LB) data for the years 1947-1990. Usually, LB data for the years 1974-1977 were used to investigate the concentration-profit relationship. If any, no positive relationship was found. Mueller and Sial show that cyclical factors play a dominant role in this period and that ignoring these cyclical factors seriously distorts the concentration-profit relationship. A positive concentration-profits relationship is found when business cycle indicators are accounted for.

${ }^{5}$ In DHP (1986a and 1986b) data on 284 industries are available. However, import-sales ratios vital for a comparison to our Dutch exercises are available only for 185 industries.

${ }^{6}$ See DHP (1986a and 1986b).

${ }^{7}$ See DHP (1986a).

8 Among the 24 OECD countries, the U.S. ranks first in decreasing order of the value of GDP, whereas the Netherlands ranks ninth. The U.S, ranks 24 th and $23 \mathrm{rd}$ in decreasing order of the share of exports in GDP and that of imports in GDP, respectively. The Netherlands ranks third in both indicators of openness. The U.S. ranks sixth and the Netherlands 16 th in GDP per employee. The U.S. ranks 18 th and the Netherlands 19 th in terms of share of manufacturing employment in total employment. The sources of these 1989 rankings are the OECD Economic Surveys (1992) and the OECD National Accounts (1990). The U.S. is atypical when it comes to size and openness. The Netherlands is atypical when it comes to openness, ranking third after Belgium and Ireland.

${ }^{9}$ Published sources are Production Statistics Manufacturing Industry, Statistics on Fixed Capital Formation in Industry and Monthly Bulletin of Price Statistics. Unpublished sources are also used.

${ }^{10}$ Notoriously difficult industries like the multinational petroleum industry and the so-called 'other' manufacturing industries (i.e. 'not-elsewhere classified' categories) have been left out.

${ }^{11}$ Moreover, Dutch gross labour costs are generally higher than their American counterparts because of the traditionally strong bargaining position of unions and the extremely high tax rates. American industry has also profited from the huge influx of low-wage immigrants. The strength of the American economy is witnessed by the ability to absorb this influx.

${ }^{12}$ See Salinger (1990, Table 1, p. 302).

${ }^{13}$ The U.S. import-sales ratio grows from an average of 0.04 in the period $1958-1965$ to an average of 0.08 in the period 1974-1981 (see DHP, 1986a, Table 6, p. 12).

${ }_{14}$ A Chow-test on equality of coefficients shows that pooling of the observations over the entire period (bottom row of Table II) has to be rejected.

${ }^{15}$ Salinger (1990) gives a similar answer. However, in the U.S. case, which he discusses, the relationship is significant and stable in the period from 1971 to 1984.

${ }^{16}$ The $S$ of $A / S$ refers to the value of sales whereas the $S$ of $I / S$ refers to domestic sales + imports. Also, elsewhere the DHP terminology is somewhat careless: output is referred to as $Q$ in $K / Q$ and as $Y$ in $Y / Y$. In our Dutch definition $Y=$ output and $S=$ domestic sales + imports.

17 The variable to be explained, price-cost margin, is identical to that defined in DHP (1986a, p. 4).

${ }^{18}$ Operating expenses include advertising expenses, but also renting and leasing of capital goods, insurance and banking costs, maintenance costs, expenses on automation (no investments), travel, education, transportation, etc. Approximately $10 \%$ of the operating expenses are spent on advertising. ${ }^{19}$ A Wharton index is computed by plotting time series of average value-added. The straight line through the peaks is assumed to correspond to a capacity utilization of $100 \%$. The capacity utilization 
is defined as the ratio between the average value-added and the corresponding value of the straight line.

${ }^{20}$ Both OLS and FE results are presented, because the key finding of DHP that import competition increases with concentration is based only on the OLS results.

${ }^{21}$ In Table II and equation (2) the coefficient of $G I / Y$ is significant.

${ }^{22}$ However, the results in DHP (1987), where the capacity utilization in total manufacturing is used as a measure of aggregate demand, show that American price-cost margins are influenced by this aggregate demand measure too.

${ }^{23}$ See Schmalensee (1989, p. 977) for more references.

${ }^{24}$ In Prince and Thurik (1992) it is reported that aggregate sales fluctuation and aggregate capacity utilization in the Netherlands fail to contribute to the explanation of price-cost margin movements when industry-specific sales fluctuation and capacity utilization are also taken into account.

${ }^{25}$ It may prove worthwhile to construct comparable indicators in which developments in the Netherlands' main export partners like neighbouring countries such as Germany, Belgium, France and the U.K. are also accounted for.

${ }^{26}$ Again the $t$-values are computed from heteroskedasticity-consistent standard errors. Indices $i$ and $t$ are omitted for convenience.

${ }^{27}$ Following the entry deterrence interpretation of recent investments in capital goods, we may conclude that their capability to deter entry is certainly not diminished when demand is rising. On the contrary, incumbents enjoy the opportunity 'to take it all' in business cycle upswings.

${ }^{28}$ It is noteworthy that there is no difference between the coefficient of operating expenses in consumer goods industries and that in producer goods industries. Usually, there is an apparent difference between consumer goods industries and producer goods industries with respect to the relation between advertising intensity and profitability. See Schmalensee $(1989$, p. 979) for references to a negative relation between profitability and advertising intensity in producer goods industries. See also DHP (1986a, Table 7, p. 13). Advertising in manufacturing industries may not always be an adequate representation of selling activities. Furthermore, there is no difference between the coefficient of industry-specific demand growth in consumer goods industries and that in producer goods industries. Under the assumption that the bargaining position of buyers depends on the demand situation, one would expect a larger demand influence in producer goods industries. Also Schumacher (1991) finds no empirical support in a similar test for U.S. industries (1977 and 1982).

${ }^{29}$ See, for example, Collins and Preston $(1969$, p. 278), Kotler (1980, pp. 267-269) and Porter (1974, p. 419).

30 A similar result can be obtained from the OLS-estimations of DHP (1986a, Table 7, p. 13). See also Schumacher (1991, Table 2, p. 282).

${ }_{31} \partial P C M / \partial(G I / Y)=0.02+0.05(V / V)$ in the first period and equals $0.05+0.22(\dot{V} / V)$ in the second.

32 In Thurik and Van der Hoeven (1989) it was shown that large Dutch manufacturing firms profit from exports as opposed to small ones. However, a different model and a smaller data set were employed.

${ }^{33}$ We would like to thank Bert Menkveld for his assistance on this part of the analysis.

${ }^{34}$ This can be concluded from the evaluation of $\partial P C M / \partial U$ at the sample means for $C 4$ and $K / Q$ for both the OLS and the FE estimations. Moreover, in the early 1958-1969 period DHP (1986a, Table 5 , p. 12) report a distinct procyclical pattern, whereas in the later 1970-1981 period no distinct autonomous pattern can be detected.

\section{References}

Caves, R. E. (1985) 'International trade and industrial organization: problems, solved and unsolved', European Economic Review 28, 377-395.

Collins, N. R. and Preston, L. E. (1969), 'Price-cost margins and industry structure', Review of Economics and Statistics 51, 271-286.

Cubbin, J. S. (1988) Market Structure and Performance - The Empirical Research, Chur: Harwood Academic Publishers.

De Jong, H. W. (1991) 'The takeover market in Europe: control structures and the performance of large companies compared', Review of Industrial Organization 6, 1-18. 
Domowitz, 1., Hubbard, R. G. and Petersen, B. C. (1986a) 'Business cycles and the relationship between concentration and price-cost margins', Rand Journal of Economics 17, 1-17.

Domowitz, I., Hubbard, R. G. and Petersen, B. C. (1986b) 'The intertemporal stability of the concentration-margins relationship', Journal of Industrial Economics 35, 13-34.

Domowitz, I., Hubbard, R. G. and Petersen, B. C. (1987) 'Oligopoly supergames: some empirical evidence on prices and margins', Journal of Industrial Economics 35, 379-398.

Frantzen, D. J. (1986) 'The cyclical behaviour of manufacturing prices in a small open economy', Journal of Industrial Economics 34, 389-408.

Geroski, P. A. (1982) 'Simultaneous equations models of the structure-performance paradigm', European Economic Review 19, 145-158.

Ginsburgh, V. and Michel, P. (1988) 'Adjustment costs, concentration and price behaviour', Journal of Industrial Economics 36, 477-481.

Hutchinson, R. W. (1981) 'Price-cost margins and manufacturing industry structure', European Economic Review 16, 247-267.

Khalilzadeh-Shirazi, J. (1974) 'Market structure and price-cost margins in United Kingdom manufacturing industries', Review of Economics and Statistics 56, 67-76.

Kotler, P. (1980) Principles of Marketing, New Jersey: Englewood Cliffs.

Kwoka, J. E,, Jr. (1979) 'The effect of market share distribution on industry performance', Review of Economics and Statistics 61, 101-109.

Martin, S. (1988) Industrial Economics, New York: Macmillan Publishing Company.

Mueller, W. F, and Sial, M. H. (1993) 'Cyclical variation in the profit-concentration relationship', Review of Industrial Organization 8, 277-291.

Neumann, M., Böbel, I. and Haid, A. (1983) 'Business cycle and industrial market power: an empirical investigation for West German industries, 1965-1977', Journal of Industrial Economics 32, 187-196.

Odagiri, H. and Yamashita, T. (1987) 'Price mark-ups, market structure and business fluctuations in Japanese manufacturing industries', Journal of Industrial Economics 35, 317-331.

Pagoulatos, E. and Sorensen, R. (1976) 'Foreign trade, concentration and profitability in open economies', European Economic Review 8, 255-267.

Porter, Michael E. (1974) 'Consumer behavior, retailer power and market performance in consumer goods industries', Review of Economics and Statistics 56, 419-439.

Prince, Y. M. and Thurik, A. R. (1992) 'Price-cost margins in Dutch manufacturing: effects of concentration, business cycle and international trade', De Economist 140, 310-335.

Prince, Yvonne and Thurik, Roy (1993) 'Firm-size distribution and price-cost margins in Dutch manufacturing", Small Business Economics 5, 173-186.

Pugel, T. A. (1980) 'Foreign trade and U.S. market performance', Joumal of Industrial Economics 29, 119-129.

Salinger, Michael (1990) The concentration-margins relationship reconsidered, in M. N. Baily and C. Winston (eds), Brookings Papers on Economic Activity: Microeconomics 1990, Washington D.C.: Brookings Institution, 287-335.

Scherer, F. M. and Ross, David (1990) Industrial Market Structure and Economic Performance, Boston: Houghton Mifflin Company.

Schmalensee, R. (1989) Inter-industry studies of structure and performance, in R. Schmalensee and R. D. Willig (eds), Handbook of Industrial Organization, Vol. II, Amsterdam: Elsevier Science Publishers, 952-1009.

Schumacher, Ute (1991), Buyer structure and seller performance in U.S. manufacturing industries, Review of Economics and Statistics 73, 277-284.

Thurik, A.R. and van der Hoeven, W. H. M. (1989) 'Manufacturing margins: differences between small and large firms', Economics Letters 29, 353-359.

Van Nieuwkerk, Marius and Sparling, Robert P. (1985) The Netheriands International Direct Investment Position, Monetary Monographs no. 4, De Nederlandsche Bank.

White, H. (1980) 'A heteroskedasticity-consistent covariance matrix estimator and a direct test for heteroskedasticity', Econometrica 48, 817-838. 